\title{
THE THERAPEUTIC EFFECTS OF SPORTS ON ARTERIAL STIFFNESS
}

\author{
OS EFEITOS TERAPÊUTICOS DO ESPORTENA RIGIDEZ ARTERIAL \\ LOSEFECTOS TERAPÉUTICOS DEL DEPORTE EN LA RIGIDEZ ARTERIAL
}

Original Article

ARTIGo Original

Artículo Original

\author{
Qi Huang ${ }^{1}$ (D) \\ (Physical Education Professional) \\ Xiaowei Zou² (D) \\ (Physician) \\ Zhijun $\mathrm{Ma}^{3}$ (ID) \\ (Physical Education Professional) \\ 1. Department of Physical \\ Education, Heilongjiang Bayi \\ Agricultural University Daqing, \\ Heilongjiang, China. \\ 2. Department of English, College \\ of Humanities, Heilongjiang Bayi \\ Agricultural University, Daqing, \\ Heilongjiang, China. \\ 3. Sport institute/college, \\ Mudanjiang Normal University, \\ Mudanjiang, China.
}

\section{Correspondence}

Daqing, Heilongjiang, 163319,

China.bynd12345678@126.com

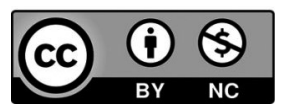

\begin{abstract}
Introduction: Cardiovascular disease has become a significant condition affecting human health. Increased arterial stiffness is a leading stage in the occurrence and development of many cardiovascular diseases. Objective: To observe the effect of different acute exercise programs on arterial stiffness of healthy young people under the same amount of exercise. Methods: We selected 16 healthy boys to conduct a blank control test, continuous exercise test, and intermittent exercise. They were divided into blank schemes. Car plan and running plan. Arterial stiffness was repeatedly measured immediately after exercise and 40 minutes after the end. Results: In the three exercise intervention experiments, the heart-ankle vascular index decreased significantly immediately after exercise. After 60 minutes of rest, the heart-ankle vascular index rebounded. Conclusion: Physical exercise can significantly reduce arterial stiffness. Changing the training intensity in sports with the same target heart rate does not affect arterial stiffness. Level of evidence Il; Therapeutic studies - investigation of treatment results.
\end{abstract}

Keywords: Arteriosclerosis; Sports; Vascular stiffness.

\section{RESUMO}

Introdução: Doenças cardiovasculares tem se tornado uma condição importante afetando a saúde humana. O aumento da rigidez arterial é uma etapa determinante na ocorrência e no desenvolvimento de muitas doenças cardiovasculares. Objetivo: Observar o efeito de diferentes programas de exercício intenso na rigidez arterial de jovens saudáveis praticando a mesma quantidade de exercício. Métodos: Selecionamos 16 rapazes saudáveis para conduzir um ensaio em branco, testes com exercícios e exercícios intermitentes. Os indivíduos foram divididos em amostras em branco, plano xxx e plano de corrida. A rigidez arterial foi medida repetidas vezes imediatamente após o exercício e 40 minutos após. Resultados: nos três experimentos de intervenção, o índice vascular cardíaco-tornozelo diminuiu consideravelmente imediatamente após o exercício. Após 60 minutos de descanso, o índice vascular cardíaco-tornozelo se recuperou. Conclusão: Exercícios físicos podem reduzir a rigidez arterial de forma considerável. Modificar a intensidade do treino nos esportes com a mesma frequência cardíaca alvo não afeta a rigidez arterial. Nível de evidência II; Estudos terapêuticos - investigação de resultados de tratamento.

Descritores: Arteriosclerose; Esportes; Rigidez vascular.

\section{RESUMEN}

Introducción: Enfermedades cardiovasculares se han convertido en una condición importante que afecta la salud humana. El aumento de la rigidez arterial es una etapa determinante en la ocurrencia y en el desarrollo de muchas enfermedades cardiovasculares. Objetivo: Observar el efecto de diferentes programas de ejercicio intenso en la rigidez arterial de jóvenes saludables practicando la misma cantidad de ejercicio. Métodos: Seleccionamos 16 muchachos saludables para conducir un ensayo en blanco, pruebas con ejercicios y ejercicios intermitentes. Se dividieron los individuos en blanco de muestra, plan de xxx y plan de carrera. Se midió la rigidez arterial repetidas veces inmediatamente tras el ejercicio y 40 minutos después. Resultados: En los tres experimentos de intervención, el índice vascular cardiaco-tobillo disminuyó considerablemente inmediatamente tras el ejercicio. Tras 60 minutos de descanso, el índice vascular cardiaco-tobillo se recuperó. Conclusión: Ejercicios físicos pueden reducir la rigidez arterial de forma considerable. Cambiar la intensidad del entrenamiento en los deportes con la misma frecuencia cardiaca-blanco no afecta la rigidez arterial. Nivel de evidencia Il; Estudios terapéuticos - investigación de resultados de tratamiento.

Descriptores: Arteriosclerosis; Deportes; Rigidez vascular.

\section{INTRODUCTION}

Arterial stiffness has become an essential target for the prevention and treatment of cardiovascular diseases. Early intervention of arterial stiffness in healthy people is an important strategy to prevent cardiovascular disease. ${ }^{1}$ At present, our laboratory uses the Cardio-Ankle Vascular Index (CAVI) to assess arterial stiffness. The Heart-Ankle Vascular Index (CAVI) has been proved to reflect the hardness of human blood vessels, and the effect is ideal in the international scope. Earlier studies in our laboratory showed that arterial stiffness was significantly reduced immediately after cycling at low intensity for $30 \mathrm{mi}$ nutes. 40min after the end of the exercise, it returns to the fundamental value. 
Compared with a power car, running is a whole-body exercise. Studies have shown that the fat oxidation rate of untrained young women running at the same intensity is higher than cycling. The maximum fat oxidation intensity and maximum fat oxidation rate are also higher than cycling. In 40\% and 60\% heart rate reserve (HRR) exercises, the blood pressure response of cycling is more vital than that of running. In the gradient exercise test of healthy young people, the systolic blood pressure response was more substantial than that of running. Cycling is more likely to induce the burden of exercise on the human cardiovascular system than running. Therefore, we speculate that running under the same target heart rate may significantly improve arterial stiffness. ${ }^{2}$ Modern people do not have enough time to exercise due to high work pressure. It has important practical significance for people to invest the same time to get more sports income. Based on the above background, this study intends to compare the effects of powered cars and running on arterial stiffness under the premise that exercise time and target heart rate are the same. At the same time, we observe the influence of arterial stiffness by adjusting the running slope to form different degrees of squeezing.

\section{METHOD}

\section{Research object}

We recruited 16 healthy boys in sports colleges. The subjects had no diabetes, hypertension, lipid metabolism disorders, and cardiovascular diseases, and the volunteers had not taken drugs. The basic situation is shown in Table 1.

\section{Experimental design}

We use a random balanced crossover self-control design. Each subject participated in 4 intervention programs: Blank Control Program (CON), Cycling Program (CYC), Zero Incline Running Program (TM0), and 18\% Incline Running Program (TM18). In each experiment, CAVI measurement was performed at 3-time points. ${ }^{3}$ Before exercise (BL), immediately after exercise (0min), and rest $40 \mathrm{~min}$ after exercise. The exercise intensity is controlled at 35\%HRR. The CON protocol only measures arterial stiffness at the corresponding time point. CAVI evaluated arterial stiffness. We used the change in $C A V I$ relative to its baseline (ACAVI) in each scenario for statistical analysis.

To avoid the influence of exercise, diet, and other factors on CAVI, all subjects avoided strenuous exercise within 24 hours. The subjects got up on an empty stomach on the morning of the experiment and entered the laboratory to rest for at least 10 minutes, and then measured the fundamental value of arterial stiffness (BL). The volunteers then carried out cycling for 30 minutes.

\section{Exercise plan}

When the power car is moving, the subject chooses a suitable seat cushion position so that the upper limbs are at the same height. The target heart rate during exercise was 35\%HRR. This is because 30\% 39\% HRR can be used as a low-intensity exercise to enhance cardiopulmonary function. ${ }^{4}$ The pedaling frequency during exercise is 60 revolutions $/ \mathrm{min}$.

Table 1. Primary conditions of subjects $(n=16)$.

\begin{tabular}{c|c}
\hline Project & Data \\
\hline Age/year old & $20.8 \pm 0.4$ \\
\hline Age range /year old & $19 \pm 24$ \\
\hline Height $/ \mathrm{cm}$ & $174 \pm 1$ \\
\hline Weight $/ \mathrm{kg}$ & $65.1 \pm 2.1$ \\
\hline Body mass index $/\left(\mathrm{kg} / \mathrm{m}^{2}\right)$ & $21.5 \pm 0.7$ \\
\hline Basic heart rate/(times $/ \mathrm{min})$ & $59 \pm 2$ \\
\hline Systolic blood pressure $/ \mathrm{mmHg}$ & $119 \pm 2$ \\
\hline Diastolic blood pressure $/ \mathrm{mmHg}$ & $72 \pm 2$ \\
\hline
\end{tabular}

Running treadmill sports are divided into 0 slopes and 18\% slopes. The subject started walking naturally, with a stride frequency of 120 steps/ min during exercise. Monitor the subject's heart rate through the polo watch, and make the heart rate near the target heart rate.

\section{Measurement of indicators}

The subject took a prone position and stretched his limbs. We use the arterial stiffness tester $V \& 1000$ to measure the arterial stiffness of the subjects. During the measurement, the upper limb cuff was ligated to the upper arm, and the lower edge of the cuff was flat with the elbow joint. ${ }^{5}$ The lower limb cuff is ligated above the ankle joint, and the lower edge of the cuff is equal to the height of the medial malleolus. We also placed soft pads on the elbows and heels to pad up the limbs. The ECG electrodes are clamped on the left and right wrists, and the heart sound sensor is placed near the sternum angle and adjusted. In the experiment, the baseline of the heart sound is stable, and the first and second heart sounds can be distinguished as the standard. The instrument calculates CAVI by itself based on the measurement results. The higher the CAVI value, the higher the arterial stiffness and the lower the elasticity. This instrument measures heart rate and blood pressure at the same time.

\section{Hemodynamic model of arterial blood vessels}

Let's set the blood pressure to be $p$. The blood flow is $Q$. Then the radius of blood is $r$. The following Navier-Stokes's equation can describe the flow in the arterial vessel of length.

$\rho \frac{d v}{d t}+v(\nabla \square v)=-\nabla p+\mu \nabla^{2} v$

$\rho$ is the blood density. $v$ is the blood flow rate. $t$ is time. $\mu$ is the blood viscosity coefficient. Considering the symmetry of blood vessels, Equation (1) can be transformed into the following cylindrical coordinate form

$$
\frac{\partial p}{\partial z}=-\rho\left(\frac{\partial v_{z}}{\partial t}+v_{r} \frac{\partial v_{z}}{\partial r}+v_{z} \frac{\partial v_{z}}{\partial z}\right)+\mu\left(\frac{\partial^{2} v_{z}}{\partial r^{2}}+\frac{1}{r} \frac{\partial v_{z}}{\partial r}+\frac{\partial^{2} v_{z}}{\partial z^{2}}\right)
$$

$$
\frac{\partial p}{\partial r}=-\rho\left(\frac{\partial v_{r}}{\partial t}+v_{r} \frac{\partial v_{r}}{\partial r}+v_{z} \frac{\partial v_{r}}{\partial z}\right)+\mu\left(\frac{\partial^{2} v_{r}}{\partial r^{2}}+\frac{1}{r} \frac{\partial v_{r}}{\partial r}+\frac{\partial^{2} v_{r}}{\partial z^{2}}-\frac{v_{r}}{r^{2}}\right)
$$

Because of the continuity of the blood flow velocity vector, $V v=0$, when expanded in cylindrical coordinates, there is

$$
\frac{\partial v_{r}}{\partial r}+\frac{v_{r}}{r}+\frac{\partial v_{z}}{\partial z}=0
$$

Ignoring the more minor terms in equations (2) and (3) can be obtained

$$
\begin{aligned}
& \frac{\partial p}{\partial z}=-\rho \frac{\partial v_{z}}{\partial t}+\mu\left(\frac{1}{r} \frac{\partial v_{z}}{\partial r}+\frac{\partial^{2} v_{z}}{\partial z^{2}}\right) \\
& \frac{\partial p}{\partial r}=-\rho \frac{\partial v_{r}}{\partial t}+\mu\left(\frac{1}{r} \frac{\partial v_{r}}{\partial r}+\frac{\partial^{2} v_{r}}{\partial z^{2}}-\frac{v_{r}}{r^{2}}\right)
\end{aligned}
$$


The radial velocity and acceleration of blood flow are minimal, and the blood vessel wall motion is small. Then the radial velocity of blood flow can be solved as

$$
v_{r}=-r \frac{\partial v_{z}}{\partial z}
$$

Visible

$$
v_{r}=\infty \Delta Q
$$

Where $Q$ is the blood flow, and $Q=v A$, where $A$ is the cross-sectional area of the blood vessel. If the linear stress-strain law is used to describe the deformation of the blood vessel wall caused by the pressure of the blood flow, then there are

$$
v_{r}=\frac{d r}{d t} \infty \frac{d p}{d t}
$$

From equations (8) and (9), blood pressure $p$ and blood flow $Q$ must satisfy the following relationship

$$
\Delta p=\frac{1}{C} \int \Delta Q d t
$$

Where $C$ is a parameter describing the compliance of the blood vessel, $C=\frac{3 \pi r^{3} l}{2 E d}$ and $E$ are the elastic modulus, and $d$ is the thickness of the blood vessel wall.

\section{Statistical methods}

All measurement data are expressed as mean \pm standard error. Two-factor repeated-measures ANOVA analyzed the changes of CAVI over time in 4 experimental days. We used the Bonferroni post-test to determine whether the differences between different experiments simultaneously were significant. ${ }^{6} P<0.05$ indicates that the difference is statistically significant.

\section{RESULTS}

\section{The influence of different exercise methods on heart rate and blood pressure}

The subject's heart rate increased significantly after cycling and running, and the subject's pulse pressure increased. The systolic blood pressure also increased slightly and then decreased (Table 2).

\section{The effect of different exercise styles on the hardness of healthy boys in swimming wall?}

In the CON scheme, ACAVI remained unchanged, and it was $(0.0 \pm 0.0)$ $(0.1 \pm 0.1)$ and $(0.0 \pm 0.1)$ at $B L, 0 \mathrm{~min}$, and $40 \mathrm{~min}$, respectively. In the CYC regimen, ACAVI dropped from baseline to $(-1.1 \pm 0.1)$ immediately after exercise. Recovered to baseline $(-0.2 \pm 0.1)$ at $40 \mathrm{~min}$. In the TMO scheme, ACAVI dropped to $(-1.2 \pm 0.1)$ at 0 min and recovered to $(-0.6 \pm 0.1)$ at 40 min. In the TM18 protocol, ACAVI dropped to $(-1.0 \pm 0.1)$ at $0 \mathrm{~min}$ and recovered to $(-0.6 \pm 0.1)$ at $40 \mathrm{~min}$. ACAVI in the CYC group recovered to the basic level, while TM0 and TM18 remained low. There was no significant difference between TM0 and TM18 groups. The specific data is shown in Figure 1.
Table 2. The influence of different exercises on heart rate and blood pressure.

\begin{tabular}{c|c|c|c}
\hline Index & BL & 0min & 40min \\
\hline CON & $59 \pm 1$ & $59 \pm 2$ & $58 \pm 2$ \\
\hline CYC & $61 \pm 2$ & $11 \pm 4$ & $62 \pm 2$ \\
\hline TMO & $59 \pm 3$ & $113 \pm 4$ & $65 \pm 2$ \\
\hline TM18 & $59 \pm 2$ & $113 \pm 5$ & $64 \pm 2$ \\
\hline Systolic blood pressure/mmHg & & & \\
\hline CON & $119 \pm 2$ & $115 \pm 2$ & $117 \pm 3$ \\
\hline CYC & $117 \pm 3$ & $124 \pm 3$ & $117 \pm 3$ \\
\hline TMO & $117 \pm 3$ & $124 \pm 3$ & $117 \pm 3$ \\
\hline TM18 & $117 \pm 2$ & $123 \pm 4$ & $116 \pm 3$ \\
\hline Diastolic blood pressure $/ \mathrm{mmHg}$ & & & \\
\hline CON & $72 \pm 2$ & $70 \pm 1$ & $70 \pm 2$ \\
\hline CYC & $70 \pm 2$ & $71 \pm 2$ & $69 \pm 1$ \\
\hline TMO & $71 \pm 2$ & $73 \pm 2$ & $71 \pm 2$ \\
\hline TM18 & $68 \pm 1$ & $75 \pm 2$ & $69 \pm 2$ \\
\hline
\end{tabular}

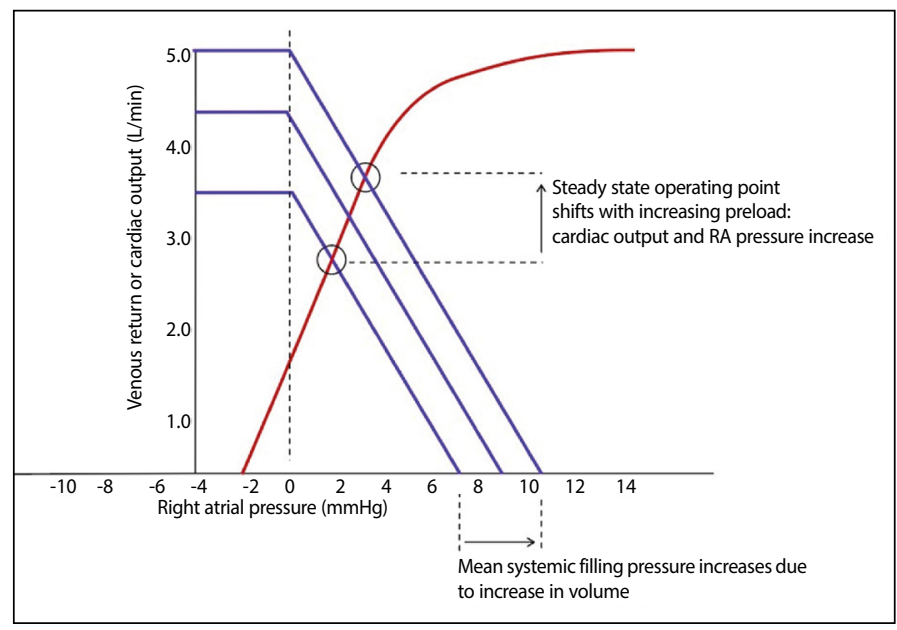

Figure 1. The impact of different exercises on ACAVI.

\section{DISCUSSION}

\section{The effect of running and cycling on arterial stiffness}

Heart rate during exercise is widely used to monitor exercise intensity. According to the American Academy of Sports Medicine guidelines on exercise prescriptions, HRR can be better used to formulate exercise prescriptions when considering exercise intensity. Because considering the subject's age and resting heart rate makes the results more accurate. So, in this experiment, we also use heart rate to monitor exercise intensity. A higher-intensity exercise prescription will reduce people's compliance. ${ }^{8}$

Experiments have shown that the blood pressure response of cycling is more robust than running in $40 \%$ and $60 \%$ HRR sports. In the gradient exercise test of healthy young people, the systolic blood pressure response was more substantial than that of running. Therefore, cycling is more likely to induce the burden of exercise on the human cardiovascular system than running. ${ }^{9}$ We infer that the change in arterial stiffness caused by exercise has no direct causal relationship with blood pressure response and exercise in the cardiovascular system.

The average maximum oxygen uptake during running is $17 \%$. This is greater than the maximum oxygen uptake during cycling. Its maximum heart rate is correspondingly large. Therefore, we speculate that under the same target heart rate, the effect of running on arterial stiffness is better than pedaling. This may be related to the maximum oxygen uptake during the process.

\section{The effect of different running slopes on arterial stiffness}

The pedaling frequency can be adjusted during cycling. Our previous studies have shown that higher pedaling frequency significantly affects 
reducing arterial stiffness in healthy young people. Excluding other possible influencing factors besides frequency, we use a $120 \mathrm{step} / \mathrm{min}$ exercise test in treadmill running.

In the design of this study, the two slopes of running exercises selected a fixed step frequency. Different slopes formed the pressure of the muscles on the arteries under different muscle contractions. ${ }^{10}$ This helps to observe the effect of improving the stiffness of the arteries. Although the effort is reduced, it can still optimize the effect of improving arterial stiffness. This also shows that the frequency of muscle contraction is the main factor that determines its effect on arterial stiffness.

\section{CONCLUSION}

Under the premise of the same target heart rate and exercise time, running has a better short-term effect on arterial stiffness of young men than cycling. However, under the premise of the same cadence, the change in the running slope, that is, the muscle contraction force, does not affect the effect of improving arterial stiffness.

\section{ACKNOWLEDGMENT}

This work is supported by Higher Education Teaching Reform and Research Program of Heilongjiang Province under the grant No. SJGY20180366. This work is also supported by Philosophy and Social Science Research Program of Heilongjiang Province under the grant No. 14 D039.

The work is funded by Philosophy and Social Science Research Program"Research on Construction of Sports Public Service System and Mobile Platform", under the grant number 19TYE315.

All authors declare no potential conflict of interest related to this article

AUTHORS' CONTRIBUTIONS: Each author made significant individual contributions to this manuscript. Qi Huang: writing and performing surgeries; Xiaowei Zou: data analysis and performing surgeries, Zhijun Ma: article review, and intellectual concept of the article.

\section{REFERENCES}

1. Way KL, Sultana RN, Sabag A, Baker MK, Johnson NA. The effect of high Intensity interval training versus moderate intensity continuous training on arterial stiffness and $24 \mathrm{~h}$ blood pressure responses: A systematic review and meta-analysis. J Sci Med Sport. 2019;22(4):385-91. doi: https:// doi.org/10.1016/j.jsams.2018.09.228

2. Tomschi F, Ottmann H, Bloch W, Grau M, Predel HG. Brachial and central blood pressure and arterial stiffness in adult elite athletes. Eur J Appl Physiol. 2021;121(7):1889-98. doi: https://doi.org/10.1007/ s00421-021-04662-z

3. Amorim S, Rolnick N, Schoenfeld BJ, Aagaard P. Low-intensity resistance exercise with blood flow restriction and arterial stiffness in humans: A systematic review. Scand J Med Sci Sports. 2021;31(3):498-509. doi: https://doi.org/10.1111/sms.13902

4. Figueroa $A$, Okamoto $T$, Jaime $\mathrm{SJ}$, Fahs $C A$. Impact of high- and low-intensity resistance training on arterial stiffness and blood pressure in adults across the lifespan: a review. Pflugers Arch. 2019;471(3):467-78. doi: https://doi.org/10.1007/s00424-018-2235-8

5. Koshiba $\mathrm{H}$, Maeshima E. Effects of exercise intervention on arterial stiffness in middle-aged and older females: evaluation by measuring brachial-ankle pulse wave velocity and cardio-ankle vascular index. J Phys Ther Sci. 2019;31(1):88-92. doi: https://doi.org/10.1589/jpts.31.88

6. Ceciliato J, Costa EC, Azevêdo L, Sousa JC, Fecchio RY, Brito LC. Effect of resistance training on arterial stiffness in healthy subjects: a systematic review and meta-analysis. Curr Hypertens Rep. 2020;22(8):51. doi: https://doi.org/10.1007/s11906-020-01065-x

7. Kim DK, ParkWH. The relationship between cardiorespiratory fitness and arterial stiffness in middleaged men with abdominal obesity. Metab Syndr Relat Disord. 2019 Mar; 17(2):97-101. doi: https:// doi.org/10.1089/met.2018.0068.

8. Noortman LCM, Haapala EA, Takken T. Arterial stiffness and its relationship to cardiorespiratory fitness in children and young adults with a fontan circulation. Pediatr Cardiol. 2019;40(4):784-91. doi: https://doi.org/10.1007/s00246-019-02065-8

9. Lee SH, Scott SD, Pekas EJ, Lee S, Lee SH, Park SY. Taekwondo training reduces blood catecholamine levels and arterial stiffness in postmenopausal women with stage-2 hypertension: randomized clinical trial. Clin Exp Hypertens. 2019;41(7):675-81. doi: https://doi.org/10.1080/10641963.2018.1539093

10. Verwoert GC, Jorstad HT. Mixed signals: arterial stiffness and elite sports. Cardiology. 2021;146(1):127-9. doi: https://doi.org/10.1159/000511491. 